INSTITUT NATIONAL DE LA STATISTIQUE ET DES ETUDES ECONOMIQUES

Série des Documents de Travail du CREST

(Centre de Recherche en Economie et Statistique)

\title{
$n^{\circ}$ 2005-08
}

\section{Does Entry Improve Welfare? A General Equilibrium Approach of Competition Policy}

B. CRETTEZ

M.-C. FAGART2

Les documents de travail ne reflètent pas la position de l'INSEE et n'engagent que leurs auteurs.

Working papers do not reflect the position of INSEE but only the views of the authors.

\footnotetext{
${ }^{1}$ LIBRE, University of Franche-Comté.

2 LEI, University of Rouen.
} 


\title{
Résumé
}

Cet article étudie un modèle d'équilibre général avec concurrence imparfaite. Les entreprises ont des rendements constants, elles adoptent un comportement de price taker sur le marché de l'input et se font concurrence en quantité (à la Cournot) sur le marché du produit. On suppose qu'il existe un consommateur représentatif. On montre qu'une augmentation du nombre d'entreprises sur un marché n'augmente pas toujours le bien-être, remettant en cause l'idée selon laquelle les fusions sans synergies de coûts sont néfastes pour le consommateur.

\begin{abstract}
We consider a general equilibrium model under imperfect competition. Firms have constant returns, they are price taker in the input market and compete à la Cournot in the product market. We assume a representative consumer exists. We show that an increase in the number of firms of a given market does not always improve welfare, challenging the common idea according to which mergers with no cost synergy are not desirable for the consumer.
\end{abstract}

Key words : Competition à la Cournot, competition policy, general equilibrium and imperfect competition, efficiency

JEL Classification: D50, L13, L40 


\section{Introduction}

The theory of competition policy aims at understanding how oligopolistic industries work and at studying what kind of competition policy can enhance efficiency and welfare. In practice, competition policy comprises of the enforcement of cartel law and merger control. The latter involves balancing efficiency gains (due to technical synergies) against increase of market power in the industry.

Consequences of competition policy are mainly developped in a partial equilibrium framework, a seminal paper dealing with this issue is Farrel and Shapiro (1990). Rey (2003) provides a review of the literature originating from Farrel and Shapiro (1990).

The tradeoff between efficiency gains and increase of market power has also been investigated in a general equilibrium setting. H. Konishi, M. Okuno-Fujiwara and K. Suzumura (1990), contributes to the general equilibrium analysis of an oligopolistic economy with free entry $^{1}$. They show that a marginal decrease in the number of oligopolistic firms from the free-entry equilibrium level improves economic welfare, which extends a result already known in a partial equilibrium framework. The reason is the following. In a free-entry oligopolistic economy, average costs, which equal product prices, exceed marginal costs, which equal marginal revenues, so that there remain unexploited increasing returns. Hence, it is socially beneficial to expand the scale of production of each firm in the oligopolistic industry. ${ }^{2}$

It is not clear, however, that some pervasive unexploited increasing returns to scale exist. As Posner (2001) puts it, "the traditional industries are characterized by multiplant and multifirm production (indicating that economies of scale are limited at both the plant level and the firm level, or in other words that average total costs are rising at relatively modest output levels), stable markets, heavy capital investment, modest rates of innovation, and slow and infrequent entry and exit." ${ }^{3}$ It could then be relevant to analyze the effect of stimulating entry in industries wherein external effects do not seem to exist, without giving up a general

\footnotetext{
${ }^{1}$ The model used in the analysis by Konishi et al. relies on the following assumptions: there are two sectors producing two goods using two inputs (capital and labor). Factors are exogenously supplied and are freely mobile between the sectors. The first good is produced under increasing returns to scale due to the existence of fixed costs (this makes this industry oligopolistic). All firms in the first sector are identical and there is Cournot competition (symmetric). The second good is competitively produced under constant returns to scale. There is a single representative consumer (whose preferences are quasi-linear).

${ }^{2} \mathrm{Cf}$ their Theorem 1. A necessary and sufficient condition for a change in the number of oligopolistic firms and/or the introduction of an infinitesimal tax-subsidy scheme to be welfare-improving is that it induces an increase in the output of each oligopolistic firm.

${ }^{3}$ Traditional industries manufacture traditional physical goods such as steel, automobiles, pipe, wire, aluminum, railroad cars, roadbuilding materials, and cigarettes.
} 
equilibrium view point. In this direction, François and Horn (2000) have recognised that competition policy should take account of general equilibrium constraints. But they notice that a satisfactory analytic framework is not available so far.

This task has been recently undertaken by Neary (2002). Neary introduced the notion of general oligopolistic equilibrium (GOLE), (see Neary 2002 (a)-(b), 2003 (a)-(c)). He provides us with a new way of modeling oligopoly in general equilibrium. This view takes advantage of the fact that generally firms are large in their own market but small in the economy as a whole.

Using a convenient specification of preferences (i.e. quadratic subutility), Neary illustrates how the notion of GOLE can be fruitful in a wide range of areas (industrial organization, international trade etc...). One of the aims of Neary is to study competition policy in a tractable macro model. He obtains an interesting and surprising result: in a featureless economy (i.e without heterogeneity across production sectors), increasing the number of firms and hence competition in each sector has no effect on welfare (see Neary (2003 (b))). Neary offers the following explanation of this result (Neary, 2003 (b), page 11): "Inducing entry by firms in all sectors raises the demand for labor. Since the aggregate labor supply constraint is binding, this merely redistributes income from profits to wages without any gain in efficiency".

As shown in Crettez and Fagart (2005), under the specific assumptions used by Neary, a GOLE is Pareto efficient. It should then come as no surprise that the competition policy has no effect on welfare (in an economy with a representative agent). However, in our view, Neary's analysis demonstrates the potential usefulness of a general approach of competition policy (of course, competition policy is modelled here in an extremely simple way: a parametric increase in the number of firms). In fact, Neary shows that it is not always true that a general increase in the number of firms in an economy with oligopolistic sectors enhances welfare.

The aim of the present paper is to illustrate furthermore the usefulness of a general equilibrium approach. In this view, we work with a model which slightly differs from Neary's one. Indeed, instead of using a continuum of sectors, as Neary does, we work with a finite number of production sectors. This enables us to investigate the general effect of an increase in the number of oligopolistic firms within a particular sector. This also allows us to easily consider competitive sectors as well as non-competitive sectors. In addition, we work with general (albeit additively separable) utility functions as well as with general (Ricardian) technologies.

We show that increasing the number of firms in a given sector may improve or reduce 
welfare, depending on the sector in which the increase occurs. This result rests on the fact that, in equilibrium, some sectors over-produce compared to efficiency and some others under-produce. Increasing the number of firms in a given sector modifies the output of other sectors, enhancing welfare when a sector that previously over-produced (resp. underproduced) reduces (increases) its output, but conversely reducing welfare when a sector that under-produces reduces its output. This two phenomena generate a trade-off to evaluate the competition policy.

The plan of the paper is as follows. In the next section, we present in detail the model used in the paper. Section 3 is devoted to examples illustrating the fact that increasing the number of firms in a sector is not always welfare enhancing. The first example uses a two-sectors economy (there is imperfect competition in both sectors). The second example uses a multiple sectors economy, some of which being competitive, assuming that preferences take the Cobb Douglas form. In section 4, we present more general results with regard to the effect of competition policy. Proofs of propositions are reported in appendix.

\section{The model}

Consider a simple closed economy inhabited by a representative agent. There exist $N$ consumption goods, indexed by $k=1, . ., N$. The agent's preferences are described by a utility function denoted $U():. R_{+}^{N} \rightarrow R$, which is increasing with respect to its arguments, strictly concave and smooth. Moreover, $U($.$) is separable, that is, denoting by x_{k}$ the consumption of good $k, \frac{\partial^{2} U(.)}{\partial x_{j} \partial x_{k}}=0$ when $j \neq k$. Furthermore, we assume that for all $k, \lim _{x_{k} \rightarrow 0^{+}} \frac{\partial U}{\partial x_{k}}=+\infty$.

The agent supplies a fixed amount of labor $L$ and considers a positive price vector $\left(p_{1}, . ., p_{N}\right)$ as given. The quantities he wishes to consume maximize his utility subject to his budget constraint:

$$
\begin{aligned}
& \max U\left(x_{1, . .}, x_{N}\right) \\
& \text { s.t } \sum_{k} p_{k} x_{k} \leq R,
\end{aligned}
$$

where $R$ denotes his income, which is equal to the sum of wages and profits. This problem has an interior solution provided that $R$ is positive. A standard reasoning shows that there exists $\lambda>0$ such that, given prices and income, the agent's optimal choice $x=\left(x_{1}, x_{2}, . ., x_{N}\right)$ solves (2) and (3) below:

$$
U_{k}^{\prime}\left(x_{k}\right)=\lambda p_{k},
$$


where $U_{k}^{\prime}\left(x_{k}\right) \equiv \frac{\partial U(x)}{\partial x_{k}}$ or, after calculating the multiplier $\lambda$

$$
U_{k}^{\prime}\left(x_{k}\right)=p_{k} \frac{\sum_{j} U_{j}^{\prime}\left(x_{j}\right) x_{j}}{R} .
$$

We can also solve this system in terms of prices rather than quantities. The inverse demand functions $P_{k}\left(x_{1}, x_{2}, . ., x_{N}, R\right), k=1, . ., N$ are the solution of (2) and (3), given income and quantities. We obtain:

$$
P_{k}(x, R)=\frac{R U_{k}^{\prime}\left(x_{k}\right)}{\sum_{j} U_{j}^{\prime}\left(x_{j}\right) x_{j}} .
$$

and a direct calculation gives the elasticity of the inverse demand function of good $k$ :

$$
\sigma_{k}(x)=\frac{\partial P_{k}(x, R)}{\partial x_{k}} \frac{x_{k}}{P_{k}(x, R)}=\frac{x_{k} U_{k k}^{\prime \prime}\left(x_{k}\right)}{U_{k}^{\prime}\left(x_{k}\right)}-\frac{x_{k}\left\{U_{k}^{\prime}\left(x_{k}\right)+x_{k} U_{k k}^{\prime \prime}\left(x_{k}\right)\right\}}{\sum_{j} x_{j} U_{j}^{\prime}\left(x_{j}\right)}
$$

where $U_{k k}^{\prime \prime}\left(x_{k}\right) \equiv \frac{\partial^{2} U(x)}{\partial x_{k}^{2}}$. Let us denote in what follows :

$$
r_{k}\left(x_{k}\right) \equiv \frac{x_{k} U_{k k}^{\prime \prime}\left(x_{k}\right)}{U_{k}^{\prime}\left(x_{k}\right)} \text { and } \theta_{k} \equiv \frac{x_{k} U_{k}^{\prime}\left(x_{k}\right)}{\sum_{j} x_{j} U_{j}^{\prime}\left(x_{j}\right)},
$$

where $\theta_{k}$ is the share of good $k$ in total expenditures. We shall assume that $r_{k}^{\prime} \leq 0^{4}$. The elasticity of the inverse demand function of good $k$ can be expressed more easily as

$$
\sigma_{k}=r_{k}-\left(1+r_{k}\right) \theta_{k}
$$

We turn now to the production side. Technology is Ricardian, labor is the sole input and firms are identical in each sector. Let $w$ the wage rate, the unit cost of firms in sector $k$ is $\alpha_{k} w, k=1, . ., N$, where $\alpha_{k}$ is a positive technical coefficient. We let $n_{k}$ be the number of firms in sector $k$. We assume that these numbers of firms are exogenous (there is no free entry). Firms maximize profits taking both the wage and a subjective demand function $P_{k}^{e}(y)$ - in each market $k$ as given.

There is a subset $I$ of sectors where firms compete à la Cournot, and each of them plays its best response to the total quantity produced by his competitors. Denoting by $x_{k}$ the total quantity produced in market of good $k$, the best response of firm $i, x_{k}^{i}$, is such that:

$$
P_{k}^{e}\left(x_{k}\right)-\alpha_{k} w+x_{k}^{i} P_{k}^{e \prime}\left(x_{k}\right)=0 .
$$

\footnotetext{
${ }^{4}$ This assumption will be used in Proposition 2.
} 
Firms being identical, the Cournot equilibrium is symmetrical and the total quantity produced in market $k$ is such that

$$
P_{k}^{e}\left(x_{k}\right)-\alpha_{k} w+\frac{x_{k} P_{k}^{e \prime}\left(x_{k}\right)}{n_{k}}=0 .
$$

Moreover, assuming that:

$$
2 P_{k}^{e \prime}\left(\frac{n_{k}-1}{n_{k}} x_{k}+y\right)+y P_{k}^{e^{\prime \prime}}\left(\frac{n_{k}-1}{n_{k}} x_{k}+y\right) \leq 0 \text { for all } y \geqslant 0,
$$

ensures that firms play in equilibrium their best responses.

In others sectors, $k \notin I$, there is perfect competition and firms take prices as given, production is such that

$$
P_{k}^{e}\left(x_{k}\right)=\alpha_{k} w, k \notin I \text {. }
$$

In the spirit of Neary (2003 b) - see also Crettez and Fagart (2005) - we will consider the following concept of general equilibrium with imperfect competition. This concept derives from Negishi (1961) approach using subjective demand functions.

Definition 1- A general equilibrium with imperfect competition in sectors $k \in I$ is a price system $p_{1}, . ., p_{N}$, a wage rate, $w$, and quantities $x=\left(x_{1}, . ., x_{N}\right)$ such that:

1) the labor market clears, that is

$$
\sum_{k} \alpha_{k} x_{k}=L
$$

2) quantities solve the agent's program, given the equilibrium income $R=\sum_{k} p_{k} x_{k}$ and the equilibrium prices;

3) quantities maximize profit so equations (9) and (11) must hold true;

4) price expectations of firms and consumer are compatible: $p_{k}=P_{k}\left(x, \sum_{k} p_{k} x_{k}\right)=$ $P_{k}^{e}\left(x_{k}\right)$

5) firms neglect Ford effects, that is

$$
P_{k}^{e \prime}\left(x_{k}\right)=\frac{\partial P_{k}\left(x, \sum_{k} p_{k} x_{k}\right)}{\partial x_{k}} .
$$

In this definition, firms expect the real inverse demand function (given by (5)) in equilibrium, but do not take into account the effects of their choices on the agent's income, or more precisely, how their production decisions affect their (perceived) demand function through the distribution of dividends and wages. This assumption, as the fact that firms are price 
taker in the labor market, rests on the idea that firms are large in their market but small in the economy as a whole.

Finally, only (12) and the two equations below matter to determine equilibrium productions and prices:

$$
\begin{gathered}
p_{k}=\frac{\sum_{j} p_{j} x_{j}}{\sum_{j} U_{j}^{\prime}\left(x_{j}\right) x_{j}} U_{k}^{\prime}\left(x_{k}\right)=\alpha_{k} w \text { if } k \notin I, \\
p_{k}=\frac{\sum_{j} p_{j} x_{j}}{\sum_{j} U_{j}^{\prime}\left(x_{j}\right) x_{j}} U_{k}^{\prime}\left(x_{k}\right)=\frac{\alpha_{k} w}{\left(1+\frac{\sigma_{k}(x)}{n_{k}}\right)} \text { if } k \in I .
\end{gathered}
$$

Inspecting these equations shows that the equilibrium allocation does not change when all nominal variables are multiplied by the same positive number. As a consequence we can choose any convenient normalization device, so we adopt the following one:

$$
\sum_{j} p_{j} x_{j}=\sum_{j} U_{j}^{\prime}\left(x_{j}\right) x_{j}
$$

Equilibrium quantities and wage are thus totally described by (12) and

$$
U_{k}^{\prime}\left(x_{k}\right)=\beta_{k}(x) \alpha_{k} w \text { with } \beta_{k}(x)=1 \text { if } k \notin I \text { and } \beta_{k}(x)=\frac{n_{k}}{n_{k}+\sigma_{k}(x)} \text { if } k \in I,
$$

where $\beta_{k}(x)$ is the gross mark-up rate of the market $k$.

Finally, note that the Pareto optimum of the economy, denoted by $x_{k}^{*}, k=1, . ., N$ solves:

$$
\begin{aligned}
& \max U\left(x_{1, . .}, x_{N}\right) \\
& \text { s.t } \sum_{k} \alpha_{k} x_{k} \leq L .
\end{aligned}
$$

The solution is interior, and the optimal solution $x^{*}$ is such that (20) below holds true:

$$
\frac{U_{k}^{\prime}\left(x_{k}^{*}\right)}{\alpha_{k}}=\frac{\sum_{j} U_{j}^{\prime}\left(x_{j}^{*}\right) x_{j}^{*}}{L}, k=1, . ., N .
$$

\section{Two examples}

In this section, we illustrate the notion of general equilibrium with imperfect competition presented above. We also point out the fact that a competition policy favoring supply in a particular sector is not always welfare increasing. 


\subsection{A two sectors economy}

Assume in what follows that only two goods, good 1 and good 2, exist, and let us represent in a plane $\left(x_{1}, x_{2}\right)$ the equilibrium of the economy.

\section{Insert Graphic 1.}

Let $\mathcal{D}$ be the production frontier (defined by $\alpha_{1} x_{1}+\alpha_{2} x_{2}=L$ ) and $\mathcal{C}$ an agent's indifference curve. The Pareto optimum is the point $\left(x_{1}^{*}, x_{2}^{*}\right)$, where $\mathcal{C}$ is tangent to $\mathcal{D}$. The equilibrium productions are located on the production frontier and satisfy:

$$
\frac{U_{1}}{U_{2}}=\frac{\alpha_{1}}{\alpha_{2}} \frac{\beta_{1}}{\beta_{2}} .
$$

The equilibrium is thus efficient if and only if $\beta_{1}=\beta_{2}$, or, equivalently, if and only if the mark-up rates are equal across sectors. This is obvioulsy the case when competition is perfect in the whole economy, since $\beta_{1}=\beta_{2}=1$. But this is also possible when the two sectors compete à la Cournot. Note that whatever the utility function may be, efficiency of equilibrium occurs if the proportion between the numbers of firms in the two sectors equates the ratio of elasticities evaluated for efficient productions, that is if:

$$
\frac{n_{1}}{n_{2}}=\frac{\sigma_{1}\left(x_{1}^{*}, x_{2}^{*}\right)}{\sigma_{2}\left(x_{1}^{*}, x_{2}^{*}\right)}
$$

Assume now that the equilibrium is not efficient. If the equilibrium (represented by point $E$ in graphic 1 ) is on the left of the optimal point $\left(x_{1}^{*}, x_{2}^{*}\right)$, the mark-up in market 1 is higher than in market $2\left(\beta_{1}>\beta_{2}\right)$ and sector 2 over-produces while sector 1 under-produces compared to their efficiency levels. As a consequence, increasing production in sector 1 (hence reducing the one of sector 2) improves welfare. Indeed, differentiating welfare with respect to quantities and using equilibrium conditions (12) and (17) leads to:

$$
d W=U_{1}^{\prime} d x_{1}+U_{2}^{\prime} d x_{2}=w\left\{\beta_{1}-\beta_{2}\right\} \alpha_{1} d x_{1} .
$$

Therefore, if for instance sector 1 is characterized by the highest mark-up, (so under-produces in equilibrium), sector 2 then over-produces. Any policy which either favors production of sector 1 or discourages that of sector 2 enhances welfare. Any policy working in the opposite direction, leading sector 2 to increase production and sector 1 to reduce its own, would make the agent worse off. 


\subsection{Example 2 - Cobb Douglas utility function}

Assume now that $N$ sectors exist and the agent has preferences represented by a Cobb Douglas function:

$$
U\left(x_{1}, . ., x_{N}\right)=\sum_{k} \gamma_{k} \log x_{k} \text { with } \gamma_{k}>0 \text { and } \sum_{k} \gamma_{k}=1
$$

A straighforward computation shows that all demands have the same elasticity, equal to -1 . Equations (12) and (17) allow to determine the equilibrium allocations as follows:

$$
\begin{aligned}
x_{k} & =\frac{\gamma_{k}}{\alpha_{k}} \frac{\delta_{k} L}{\sum_{j} \gamma_{j} \delta_{j}} \text { with } \delta_{j} \equiv \frac{1}{\beta_{j}} \\
\text { that is } \delta_{j} & =\frac{n_{j}-1}{n_{j}} \text { if } k \in I \text { and } \delta_{j}=1 \text { otherwise. }
\end{aligned}
$$

And the equilibrium value of welfare is:

$$
W=\sum_{k} \gamma_{k} \log \left(\frac{\gamma_{k} L}{\alpha_{k}}\right)+\sum_{k} \gamma_{k} \log \delta_{k}-\log \left(\sum_{k} \gamma_{k} \delta_{k}\right)
$$

Finally, note that Pareto efficiency requires that:

$$
x_{k}^{*}=\frac{\gamma_{k}}{\alpha_{k}} L
$$

\section{- Efficiency of production}

Comparing (22) and (24) allows us to express the difference between equilibrium and efficient productions in sector $k$ :

$$
x_{k}-x_{k}^{*}=\frac{\gamma_{k} L}{\alpha_{k}} \frac{\delta_{k}-\sum_{j} \gamma_{j} \delta_{j}}{\sum_{j} \gamma_{j} \delta_{j}} .
$$

Consequently, as long as $\delta_{k}$ is constant across sectors, equilibrium productions are efficient. Such a surprising property occurs not only when no imperfect competition exists, but also when competition is imperfect in all sectors, and the number of firms is the same in each market. In this case, all mark-up ratios are identical, that is $\delta_{k}=\sum_{j} \gamma_{j} \delta_{j}=\delta_{m}$ for all $k$.

When none of these conditions holds, the equilibrium allocation is inefficient, implying that some sectors produce too much in equilibrium (compared to efficiency), while the output of others is too low. More precisely, whenever $\delta_{k}>\sum_{j} \gamma_{j} \delta_{j}=\delta_{m}$, sector $k$ over-produces. Note that all competitive sectors are concerned by this over-production, but it may occur 
that some of the imperfect competitive sectors either produce efficiently (when $\delta_{k}=\delta_{m}$ ), or over-produce as competitive ones.

- Shall one encourage or discourage mergers?

Assume that the regulator can favor entry in market for good $h$ or conversely favor mergers. Increasing the number or firms increases the inverse mark-up rate $\delta_{h}$ and improves welfare if:

$$
\frac{\partial W}{\partial \delta_{h}}=\frac{\gamma_{h}}{\delta_{h}}-\frac{\gamma_{h}}{\sum_{k} \gamma_{k} \delta_{k}}>0 \text { that is if } \delta_{h}<\frac{\sum_{k \neq h} \gamma_{k} \delta_{k}}{\sum_{k \neq h} \gamma_{k}}
$$

This is equivalent to $\delta_{h}<\delta_{m}$. An increase in the number of firms $n_{h}$ improves welfare only if sector $h$ under-produces in equilibrium, compared to efficiency. Indeed, more firms in sector $h$ always imply a higher output of that sector and a smaller one in others sectors, as we have:

$$
\frac{\partial x_{h}}{\partial \delta_{h}}=\frac{\gamma_{k} L}{\alpha_{k}} \frac{\sum_{j \neq h} \gamma_{j} \delta_{j}}{\left(\sum_{j} \gamma_{j} \delta_{j}\right)^{2}}>0 \text { and } \frac{\partial x_{k}}{\partial \delta_{h}}=-\frac{\gamma_{k}}{\alpha_{k}} \frac{\gamma_{h} \delta_{j} L}{\left(\sum_{j} \gamma_{j} \delta_{j}\right)^{2}}<0
$$

When sector $h$ under-produces in equilibrium, it is efficient to stimulate the production of good $h$, even if this implies a decrease in production everywhere else. A good policy then consists in discouraging mergers in sector $h$.

The decision of the regulator with respect to mergers should then depend on the market in which they occur. When perfect competitition dominates, $\delta_{m}$ is high, increasing competition (or controlling mergers to avoid a decrease in the number of firms) in almost all markets characterized by imperfect competition makes sense. On contrary, when imperfect competition sectors dominate, $\delta_{m}$ is law, competition policy should favor mergers in markets where $\delta_{h}>\delta_{m}$ and control it otherwise.

\section{- Is perfect competition desirable for consumer?}

Imagine that an imperfect competition sector, say $h$, can be turned to be a perfect competition one. Is such a modification always desirable for the consumer? In technical terms, this amounts to compare the welfare evaluated at $\left(\delta_{1}, \ldots, \delta_{h-1}, \delta_{h}, \delta_{h+1}, \ldots, \delta_{N}\right)$ to the welfare evaluated at $\left(\delta_{1}, \ldots, \delta_{h-1}, 1, \delta_{h+1}, \ldots, \delta_{N}\right)$. It is easy to verify that $W($.$) is concave with$ respect to $\delta_{h}$, which goes to $-\infty$ when $\delta_{h}$ goes to 0 and reaches a maximum in $\delta_{h}=\delta^{*}=$ $\frac{\sum_{k \neq h} \gamma_{k} \delta_{k}}{\sum_{k \neq h} \gamma_{k}}$ (this last condition is equivalent to $\left.\delta_{h}=\delta_{m}\right)$. Consequently, there exists $\widehat{\delta}$ such 
that $0<\widehat{\delta}<\delta^{*}$ and such that:

$$
W_{\mid \delta_{h}=\widehat{\delta}}=W_{\mid \delta_{h}=1} \text { so that } W_{\mid \delta_{h}}<W_{\mid \delta_{h}=1} \Leftrightarrow \delta_{h}<\widehat{\delta}
$$

Perfect competition in market $h$ is thus desirable only if the inverse of the mark-up is not too small. Note that a mark-up rate behaviour "near the mean" $\delta_{m}$ is always prefered by the consumer to perfect competition.

\section{More General Results}

We now present more general results in line with the insights provided by our previous examples. As a first point, note that a general equilibrium with perfect competition may be Pareto efficient (Crettez and Fagart 2005). Indeed, whenever all sectors have the same markup, that is when all the $\beta_{k}$ are identical, the equilibrium productions satisfy the conditions of efficiency (20). This will arrise, however, only if imperfect competition prevail in all sectors, and if the numbers of firms are such that

$$
\frac{\sigma_{k}\left(x^{*}\right)}{n_{k}^{*}}=\frac{\sigma_{j}\left(x^{*}\right)}{n_{j}^{*}} \text { for all } k \neq j .
$$

In particular, notice that in every symmetrical economy, the equilibrium is always efficient.

What matters for inefficiency to occur is thus the fact that sectors have different mark-up rates. As a consequence, when some competitive sectors exist, the equilibrium is no longer efficient, whatever the number of firms that compete in markets. The features of inefficiency, however, differ across sectors, as stated in Proposition 1.

Proposition 1- Assume that the equilibrium is Pareto inefficient. Then there exists a number $\widehat{\beta}$ such that $\max \beta_{k}>\widehat{\beta}>\min \beta_{k}$. Sectors with mark-up $\beta_{k}$ higher than $\widehat{\beta}$ under-produce compared to their efficiency levels and sectors whith mark-up lower than $\widehat{\beta}$ over-produce.

The idea according to which competition à la Cournot reduces production compared to the efficiency level is no longer valid in a general equilibrium context. Indeed, assume that no competitive sector exists. In our economy, a low production implies a low employment level, so the equilibrium of the labor market requires that if some sectors under-produce in equilibrium compared to their efficiency levels, some others must over-produce. Underproduction occurs in markets in which the mark-up rates are relatively higher. Moreover, if competitive sectors coexist with non-competitive ones, we know that perfect competitive mark-up rates are all equal to the smallest feasible mark-up. Hence any competitive sector 
(strictly) over-produces and at least one sector with imperfect competition under-produces. The fact that competition is imperfect in at least one market implies that all competitive markets produce inefficiently. Surprisingly, some sectors may produce in an efficient way in equilibrium, but these efficient sectors are characterized by imperfect competition.

The value of welfare reacts to feasible changes in production in the following way:

$$
d W=\sum_{k} U_{k}^{\prime}\left(x_{k}\right) d x_{k}=\sum_{k}\left\{\frac{U_{k}^{\prime}\left(x_{k}\right)}{\alpha_{k}}-\rho\right\} \alpha_{k} d x_{k} \text { for all } \rho .
$$

Setting $\rho=\frac{U_{k}^{\prime}\left(x_{k}^{*}\right)}{\alpha_{k}}$, we obtain:

$$
d W=\sum_{k}\left\{\frac{U_{k}^{\prime}\left(x_{k}\right)}{\alpha_{k}}-\frac{U_{k}^{\prime}\left(x_{k}^{*}\right)}{\alpha_{k}}\right\} \alpha_{k} d x_{k} .
$$

Welfare is enhanced if both over-production and under-production phenomena are reduced, which means increasing production in sectors with small mark-up rates and decreasing those with high mark-up rates (see equation (17)).

How does competition policy in a given sector affect welfare? Consider a policy which favors production in sector $h$, for instance a policy prohibiting mergers. In a partial equilibrium framework, we would conclude that this would improve welfare (this is so, since consequences in other markets are disregarded). Here, what happens in other markets is crucial. Indeed, setting $\rho=\beta_{h} w$, we obtain the following expression of welfare:

$$
d W=w \sum_{k}\left\{\beta_{k}-\beta_{h}\right\} \alpha_{k} d x_{k} .
$$

Assume that an increase in the production of sector $h$ implies that firms decrease their production in all other markets (because, for instance, the wage rate increases). This generates a positive effect on welfare in all markets where $\beta_{k}<\beta_{h}$, and a negative one in all markets where $\beta_{k}>\beta_{h}$. A priori, the net effect is indeterminate except when the mark-up rate of sector $h$ is either the smallest or the highest one. In particular, favoring production in the sector with the smallest mark-up (when no competitive sectors exists) would be welfare reducing, which contradicts the partial equilibrium common view.

These conclusions, however, rest on the fact that changes in productions levels behave in a "friendly" way, that is: more firms in sector $h$ would stimulate production of good $h$ and dispress that of other goods - this case arises when the consumer preferences can be represented by a Cobb Douglas function as in the previous section. In a more general setting, cross effects affect the elasticity of the inverse demand functions, making general conclusions 
more difficult to obtain. However, Proposition 2 below confirms the main conclusions of the Cobb Douglas example.

Proposition 2: i) - Assume the general equilibrium is not efficient and no competitive sector exists. Then there exists two (non empty) subsets of sectors, such that increasing the number of firms in a sector which belongs to the first (resp. second) subset improves (resp. decreases) welfare.

ii )- Assume the general equilibrium is not efficient. Then, there exists a system of weights $\eta_{k}>0$, with $\sum_{k} \eta_{k}=1$ such that, if the variables $r_{k}$ (see equation (7)) are identical across sectors in equilibrium, increasing the number of firms in market $j$ improves welfare if an only if the mark-up $\beta_{j}>\sum_{k} \eta_{k} \beta_{k}$.

Point $i$ ) confirms the intuitions given above. When all sectors are concerned by imperfect competition, entry must be favored in some markets and discouraged in others, hence entry has opposite effects on welfare depending on the concerned market. However, in a general setting, it is difficult to identify how cross effects play in the whole economy (i.e. how the production of a given market reacts to an increase in the number of firms in sector $h$ ). Point ii) allows us to precise that the sectors in which entry is desirable (respectively not desirable) are those which have low (resp. high) mark-up rates and that this conclusion holds even when perfect competition prevails in some sectors.

The separability of $U($.$) is a key assumption to obtain Proposition 2, which allows to$ differentiate easily equilibrium conditions (17) and (12) with respect to numbers of firms in imperfect competition sectors. In a second step, we need to solve this linear system, and assuming that $r_{k}^{\prime} \leq 0$ provides a tractable resolution (by ensuring a parameter cannot equate zero). Note that, despite these simplifying assumptions, the proof of Proposition 2 is very long.

Furthermore, even if the condition according to which $r_{k}$ is identical across sectors may seems restrictive, it is satisfied for a large class of utility functions, the CRRA functions, which are frequently used in macroeconomic papers:

$$
U(x)=\sum_{k} \gamma_{k} \frac{\left(x_{k}\right)^{\rho}}{\rho}, \text { with } \rho<1 .
$$

Finally, note that all terms in $\eta_{k}$ are "observable" in principle, so our threshold could be 
empirically measured. Indeed,

$$
\begin{aligned}
\eta_{k} & \equiv \frac{\frac{\alpha_{k} x_{k}}{A_{k}}}{\sum_{j} \frac{\alpha_{j} x_{j}}{A_{j}}} \\
\text { with } A_{k} & \equiv r_{k}+\frac{\left[\left(1-\theta_{k}\right) r_{k}^{\prime} x_{k}-\left(1+r_{k}\right)^{2} \theta_{k}\right]}{n_{k}+\sigma_{k}} \text { if } k \in I \text { and } A_{k} \equiv r_{k} \text { otherwise }
\end{aligned}
$$

The variables in these expressions are technical coefficients $\left(\alpha_{k}\right)$, production levels $\left(x_{k}\right)$, the elasticity of the marginal utility of good $k$ (as well as the derivative of the latter with respect to $x_{k}$, which implies however an evaluation of the third derivative of the original utility function), budget coefficient $\left(\theta_{k}\right)$, and the elasticity of the "perceived" demand function.

What does Proposition 2 state in terms of competition policy?

More competition is not always desirable. The key point is that a sector in which competition is imperfect may over-produce with respect to the efficient level. As a consequence, even if other sectors are disregarded (because one could consider that what happens in a sector has negligible effects on others), mergers are desirable in such sectors, while they reduce firms' supply.

Any decision in a given sector affects the whole economy, and has positive effects in some markets and negative effects in others. Even if everything may happen in a general equilibrium model, which is due to cross effects, we obtain under simple assumptions some rather reasonable conclusions: the competition policy should stimulate supply in sectors where mark-up rates are relatively high and discourage it in others. Finally, Competition Authorities should concentrate their actions against only a small number of sectors. This implies that sectors should not be treated with equal opportunities.

Different competition policy measures are substituable. Indeed, favoring mergers in sectors with low mark-up rates works in the same direction than preventing mergers in sectors with high mark-up rates. When prohibiting mergers seems difficult, welfare could be enhanced by a policy which promotes mergers more intensively in some sectors than in others.

Our last point is that competition policy needs coordination. Indeed, prohibiting mergers in sectors with high mark-up rates increases welfare whereas prohibiting mergers in sectors with low mark-up rates decreases it. As these decisions play in opposite directions, they could neutralize each others, and finally have no impact on welfare. More coordination could thus reduce the volume of jurisprudence. 


\section{Conclusion}

This paper is an attempt to evaluate competition policy within a general equilibrium framework. To do so, we use a tractable general equilibrium model with imperfect competition, based on that used by Negishi (1961) and Neary (2003). Even if our modelisation extends that of Neary (we use more general utility functions), the facts that returns to scale are constant, that firms are symmetrical inside markets, and our assumption concerning the consumer's preferences limit the validity of our results. Despite weaknesses, the insights of general equilibrium approach differ deaply from that of partial equilibrium analysis, and call into question usual conclusions of industrial economics.

We challenged the view that increasing supply in a given sector is welfare enhancing. We also provided some conditions which enable to identify sectors where stimulating supply (or discouraging mergers) is welfare enhancing. Our results contradicts the juridical view according to which all sectors should be treated in the same way, and suggests that horizontal merger control should limit its action in sectors with high mark-up rates and disregard others. Moreover, the industrial policy should favor concentrations or collusion pratices among firms in sectors with low mark-up rates. Finally, the general equilibrium approach shows that what happens in other markets is crucial to measure how welfare varies in response to an horizontal merger. We also challenge the idea according to which anticompetitive effects of a merger could be measured on a relevant market or area, and we claim that, as long as the price of the input reacts to the merger, and attention should be extended to the whole economy.

There are two assumptions on which the analysis of this paper rests and which should be relaxed in further research. We assume a representative consumer exists and firms use the same and unique input. With several inputs and several agents, it would be possible to study the redistributive effect of competition policy. It would also be possible to address international trade issues. 


\section{Appendix}

\section{Proof of Proposition 1}

Note that $U_{k}^{\prime}\left(x_{k}\right) \geqslant$ (respectively $\leq$ ) $U_{k}^{\prime}\left(x_{k}^{*}\right)$ whatever $k$ in equilibrium implies that $x_{k} \leq$ (resp. $\left.\leq\right) x_{k}^{*} \forall k$, so is infeasible as long as the general equilibrium is not efficient. Indeed, the labour market equilibrium implies that $\sum_{k} \alpha_{k} x_{k}=\sum_{k} \alpha_{k} x_{k}^{*}$. As a consequence, there exist two goods $h \neq j$ such that $x_{h}<x_{h}^{*}$ and $x_{j}>x_{j}^{*}$, so we have:

$$
w \beta_{h}=\frac{U_{h}^{\prime}\left(x_{h}\right)}{\alpha_{h}}>\frac{U_{h}^{\prime}\left(x_{h}^{*}\right)}{\alpha_{h}}=\frac{U_{k}^{\prime}\left(x_{k}^{*}\right)}{\alpha_{k}}>w \beta_{j}=\frac{U_{j}^{\prime}\left(x_{j}\right)}{\alpha_{j}} .
$$

As a consequence, there exists a threshold $\widehat{\beta}=\frac{U_{k}^{\prime}\left(x_{k}^{*}\right)}{w \alpha_{k}}$ such that $\max \beta_{k}>\widehat{\beta}>\min \beta_{k}$ and:

$$
x_{k} \geqslant x_{k}^{*} \text { if and only if } \beta_{k} \leq \widehat{\beta} \text {. }
$$

When competitive sectors exist, the mark-up in these sectors equals 1 , so $\min \beta_{k}=1$, and the production of any competitive sector is higher than the efficient one.

\section{Proof of Proposition 2}

We prove Proposition 2 in three steps. The first step is the most difficult and the most technical one. We use equilibrium conditions to express how welfare varies when the number of firms changes in one sector. In the second and and the third ones, we turn to prove the two points of Proposition 2.

\section{FIRST STEP}

- Consider first a technical detail of calculus. Differentiating $\theta_{k}$ given in (7) (that is $\left.\theta_{k}=\frac{U_{k}^{\prime}\left(x_{k}\right) x_{k}}{\sum_{j} U_{k}^{\prime}\left(x_{j}\right) x_{j}}\right)$ gives

$$
\frac{\partial \theta_{k}}{\partial x_{k}}=\frac{\left(1+r_{k}\right) \theta_{k}\left(1-\theta_{k}\right)}{x_{k}} \text { and } \frac{\partial \theta_{k}}{\partial x_{j}}=-\frac{\left(1+r_{j}\right) \theta_{j} \theta_{k}}{x_{j}}
$$

so derivating the elasticity given by (8) (that is $\sigma_{k}=r_{k}-\left(1+r_{k}\right) \theta_{k}$ ) leads to

$$
\frac{\partial \sigma_{k}}{\partial x_{k}}=\left(1-\theta_{k}\right) r_{k}^{\prime}-\frac{\left(1+r_{k}\right)^{2} \theta_{k}\left(1-\theta_{k}\right)}{x_{k}} \text { and } \frac{\partial \sigma_{k}}{\partial x_{j}}=\frac{\left(1+r_{k}\right)\left(1+r_{j}\right) \theta_{j} \theta_{k}}{x_{j}} \text { for } j \neq k .
$$


As a consequence, we obtain that

$$
d \sigma_{k}=\sum_{k} \frac{\partial \sigma_{k}}{\partial x_{j}} d x_{j}=\left[\left(1-\theta_{k}\right) r_{k}^{\prime} x_{k}-\left(1+r_{k}\right)^{2} \theta_{k}\right] \frac{d x_{k}}{x_{k}}+\theta_{k}\left(1+r_{k}\right) \sum_{j} \theta_{j}\left(1+r_{j}\right) \frac{d x_{j}}{x_{j}} .
$$

- Let us turn now to the system of equations defining the equilibrium for given numbers of firms, that is (12) and $(17)^{5}$. Let us rewrite (17) in the following way:

$$
\begin{aligned}
\log \left(n_{k}+\lambda_{k} \sigma_{k}\right)+\log U_{k}^{\prime} & =\log \alpha_{k}+\log w+\log n_{k} \\
\text { with } \lambda_{k} & =1 \text { if } \mathrm{k} \in I \text { and } \lambda_{k}=0 \text { otherwise. }
\end{aligned}
$$

Differentiating (33) and (12) gives:

$$
\begin{gathered}
\frac{\lambda_{k} d \sigma_{k}}{n_{k}+\lambda_{k} \sigma_{k}}+r_{k} \frac{d x_{k}}{x_{k}}=\frac{d w}{w}+\left(1-\beta_{k}\right) \frac{d n_{k}}{n_{k}}, \text { and } \\
\sum_{k} \alpha_{k} x_{k} \frac{d x_{k}}{x_{k}}=0 .
\end{gathered}
$$

Finally, using (32),(34) can be written as:

$$
\begin{aligned}
& A_{k} \frac{d x_{k}}{x_{k}}+B_{k} C=\frac{d w}{w}+\left(1-\beta_{k}\right) \frac{d n_{k}}{n_{k}}, k=1, . . N \\
& \text { with } A_{k} \equiv r_{k}+\frac{\lambda_{k}\left[\left(1-\theta_{k}\right) r_{k}^{\prime} x_{k}-\left(1+r_{k}\right)^{2} \theta_{k}\right]}{n_{k}+\lambda_{k} \sigma_{k}} \\
& B_{k} \equiv \frac{\lambda_{k} \theta_{k}\left(1+r_{k}\right)}{n_{k}+\lambda_{k} \sigma_{k}} \\
& C \equiv \sum_{j} \theta_{j}\left(1+r_{j}\right) \frac{d x_{j}}{x_{j}} .
\end{aligned}
$$

We want to solve the system of equations (36) and (35) with respect to relative quantities $\frac{d x_{k}}{x_{k}}, k=1, . ., N$ to determine if the welfare is improved when the number of firms in a sector increases. Note that assuming that $r_{k}^{\prime} \leq 0$ ensures that $A_{k}<0$.

- It is not necessary to solve all the system to obtain how the welfare changes whith the number of firms. Indeed, the variation of welfare whith respect to quantities is:

\footnotetext{
${ }^{5}$ Recall that (12) is $\sum_{k} \alpha_{k} x_{k}=L$ and $(17)$ is

$$
U_{k}^{\prime}\left(x_{k}\right)=\beta_{k} \alpha_{k} w \text { where } \beta_{k}=1 \text { if } k \notin I \text { and } \beta_{k}=\frac{n_{k}}{n_{k}+\sigma_{k}} \text { if } k \in I \text {. }
$$
}




$$
\begin{aligned}
d W & =\sum_{k} U_{k}^{\prime}\left(x_{k}\right) d x_{k} \\
& =\sum_{k}\left(x_{k} U_{k}^{\prime}\left(x_{k}\right)-\rho \alpha_{k} x_{k}\right) \frac{d x_{k}}{x_{k}} \text { whatever } \rho \text { as (35) holds. }
\end{aligned}
$$

Let us introduce the following weights:

$$
\eta_{k} \equiv \frac{\frac{\alpha_{k} x_{k}}{A_{k}}}{\sum_{j} \frac{\alpha_{j} x_{j}}{A_{j}}} \text { and } \widehat{\eta}_{j} \equiv \frac{\frac{x_{k} U_{k}^{\prime}}{A_{k}}}{\sum_{j} \frac{x_{j} U_{j}^{\prime}}{A_{j}}}
$$

and note that $\eta_{k}>0, \sum_{k} \eta_{k}=1, \widehat{\eta}_{k}>0$ and $\sum_{k} \widehat{\eta}_{k}=1$. Moreover,

$$
\widehat{\eta}_{k}=\frac{\eta_{k} \beta_{k}}{\sum_{j} \eta_{j} \beta_{j}}=\frac{\eta_{k} \beta_{k}}{\beta_{m}} \text { where } \beta_{m} \equiv \sum_{j} \eta_{j} \beta_{j} .
$$

The expression of welfare can be simplified using the weights $\eta_{k}$ and $\widehat{\eta}_{k}$ as follows:

$$
\begin{aligned}
d W & =\sum_{k}\left(\widehat{\eta}_{k} \sum_{j} \frac{x_{j} U_{j}^{\prime}}{A_{j}}-\eta_{k} \rho \sum_{j} \frac{\alpha_{j} x_{j}}{A_{j}}\right) A_{k} \frac{d x_{k}}{x_{k}} \\
& =\sum_{j} \frac{x_{j} U_{j}^{\prime}}{A_{j}} \sum_{k}\left(\widehat{\eta}_{k}-\eta_{k}\right) A_{k} \frac{d x_{k}}{x_{k}} \text { for } \rho=\frac{\sum_{j} \frac{x_{j} U_{j}^{\prime}}{A_{j}}}{\sum_{j} \frac{\alpha_{j} x_{j}}{A_{j}}}
\end{aligned}
$$

As multiplying (36) by $\left(\widehat{\eta}_{k}-\eta_{k}\right)$ and summing with respect to $k$ gives:

$$
\sum_{k}\left(\widehat{\eta}_{k}-\eta_{k}\right) A_{k} \frac{d x_{k}}{x_{k}}=-C \sum_{k}\left(\widehat{\eta}_{k}-\eta_{k}\right) B_{k}+\sum_{k}\left(\widehat{\eta}_{k}-\eta_{k}\right)\left(1-\beta_{k}\right) \frac{d n_{k}}{n_{k}},
$$

we can see that the key point to evaluate the effect of the increase of the number of firms is to calculate $C$ from (36) and (35).

- Multipliying (36) by $\frac{\theta_{k}\left(1+r_{k}\right)}{A_{k}}$ and summing gives:

$$
C\left[1+\sum_{k} \frac{\theta_{k}\left(1+r_{k}\right) B_{k}}{A_{k}}\right]=\frac{d w}{w} \sum_{k} \frac{\theta_{k}\left(1+r_{k}\right)}{A_{k}}+\sum_{k} \frac{\left(1-\beta_{k}\right) \theta_{k}\left(1+r_{k}\right)}{A_{k}} \frac{d n_{k}}{n_{k}}
$$

or

$$
C\left[\sum_{j} \widehat{\eta}_{j} A_{j}+\sum_{k} \widehat{\eta}_{k}\left(1+r_{k}\right) B_{k}\right]-\frac{d w}{w} \sum_{k} \widehat{\eta}_{k}\left(1+r_{k}\right)=\sum_{k}\left(1-\beta_{k}\right) \widehat{\eta}_{k}\left(1+r_{k}\right) \frac{d n_{k}}{n_{k}} .
$$


In the same manner, multiplying (36) by $\alpha_{k} x_{k}$, summing and taking into account (35) leads to:

$$
C \sum_{k} \frac{\alpha_{k} x_{k} B_{k}}{A_{k}}=\frac{d w}{w} \sum_{k} \frac{\alpha_{k} x_{k}}{A_{k}}+\sum_{k} \frac{\alpha_{k} x_{k}\left(1-\beta_{k}\right)}{A_{k}} \frac{d n_{k}}{n_{k}} ;
$$

that is:

$$
C \sum_{k} \eta_{k} B_{k}-\frac{d w}{w}=\sum_{k} \eta_{k}\left(1-\beta_{k}\right) \frac{d n_{k}}{n_{k}}
$$

And we have to solve (42) and(44) with respect to $C$.

- Taking into account (42) and(44) leads to express $C$ as :

$$
\begin{aligned}
& C \sum_{k} \widehat{\eta}_{k}\left[A_{k}+\left(1+r_{k}\right) B_{k}\right]-\sum_{j} \eta_{j} B_{j} \sum_{k} \widehat{\eta}_{k}\left(1+r_{k}\right) \\
= & \sum_{k}\left(1-\beta_{k}\right)\left\{\widehat{\eta}_{k}\left(1+r_{k}\right)-\eta_{k} \sum_{j} \widehat{\eta}_{j}\left(1+r_{j}\right)\right\} \frac{d n_{k}}{n_{k}} .
\end{aligned}
$$

Let us show that $\left[\sum_{k} \widehat{\eta}_{k}\left[A_{k}+\left(1+r_{k}\right) B_{k}\right]-\sum_{j} \eta_{j} B_{j} \sum_{k} \widehat{\eta}_{k}\left(1+r_{k}\right)\right] \neq 0$. Assume the converse was true, so the right term of (45) equates 0 , whatever the market in which the number of firms is modified. As a consequence, we would have

$$
\widehat{\eta}_{k}\left(1+r_{k}\right)=\eta_{k} \sum_{j} \widehat{\eta}_{j}\left(1+r_{j}\right) \text { for all } k \text { such that } \beta_{k}=1
$$

but this leads to

$$
\left.\sum_{k} \widehat{\eta}_{k}\left[A_{k}+\left(1+r_{k}\right) B_{k}\right]-\sum_{j} \eta_{j} B_{j} \sum_{k} \widehat{\eta}_{k}\left(1+r_{k}\right)\right]=\sum_{k} \widehat{\eta}_{k} A_{k} \neq 0
$$

which contradicts our assumption.

- Finally, taking into account the value of $C$ given in (45) in the definition of the variation of welfare given by (39) leads to

$$
\begin{aligned}
d W & =\left\{\sum_{j} \frac{x_{j} U_{j}^{\prime}}{A_{j}}\right\} \sum_{k}\left(1-\beta_{k}\right) \Gamma_{k} \frac{d n_{k}}{n_{k}} \\
\text { with } \Gamma_{k} & =\widehat{\eta}_{k}-\eta_{k}-\frac{\left\{\widehat{\eta}_{k}\left(1+r_{k}\right)-\eta_{k} \sum_{j} \widehat{\eta}_{j}\left(1+r_{j}\right)\right\} \sum_{j}\left(\widehat{\eta}_{j}-\eta_{j}\right) B_{j}}{\sum_{k} \widehat{\eta}_{j}\left[A_{j}+\left(1+r_{j}\right) B_{j}\right]-\sum_{j} \eta_{j} B_{j} \sum_{j} \widehat{\eta}_{j}\left(1+r_{j}\right)} .
\end{aligned}
$$

As a consequence, an increase in the number of firms of imperfect competitive sector $k$ enhances welfare if and only if $\Gamma_{k}>0$. 


\section{SECOND STEP : PROOF OF POINT i)}

It is easy to verify that:

$$
\begin{gathered}
\sum_{k} \Gamma_{k}=0 \\
\text { and } \sum_{k} \Gamma_{k} B_{k}=\frac{\sum_{j} \widehat{\eta}_{j} A_{j} \sum_{k}\left(\widehat{\eta}_{k}-\eta_{k}\right) B_{k}}{\sum_{j} \widehat{\eta}_{j} A_{j}+\sum_{h} \widehat{\eta}_{h}\left(1+r_{h}\right)\left(B_{h}-\sum_{j} \eta_{j} B_{j}\right)} .
\end{gathered}
$$

So another expression of $\Gamma_{k}$ is:

$$
\Gamma_{k}=\widehat{\eta}_{k}-\eta_{k}-\frac{\left[\widehat{\eta}_{k}\left(1+r_{k}\right)-\eta_{k} \sum_{j} \widehat{\eta}_{j}\left(1+r_{j}\right)\right] \sum_{k} \Gamma_{k} B_{k}}{\sum_{j} \widehat{\eta}_{j} A_{j}}
$$

Assume that no competitive sector exists. If all $\Gamma_{k}=0$ for $k \in I$, we obtain that $\sum_{k} \Gamma_{k} B_{k}=0$ so $\Gamma_{k}=\widehat{\eta}_{k}-\eta_{k}=0$. Consequently, $\widehat{\eta}_{k}=\eta_{k}$ in all sectors and efficiency is ensured, what contradicts our assumption. As a consequence, there exists two non empty subsets of sectors, such that $\Gamma_{k}>0$ in one of the subsets, and $\Gamma_{k}<0$ in the other one. This proves Point $\mathrm{i}$ of Proposition 2.

\section{THIRD STEP : PROOF OF POINT ii)}

Assume $r_{k}$ is constant across sectors. Taking into account the expression of $B_{j}$ given by (36) and the fact that $r_{k}=r$ is identical across sectors leads to express $\Gamma_{k}$ as

$$
\begin{aligned}
\Gamma_{k} & =\left(\widehat{\eta}_{k}-\eta_{k}\right)\left\{1-\frac{(1+r)^{2} \sum_{j}\left(\widehat{\eta}_{j}-\eta_{j}\right) \frac{\lambda_{j} \theta_{j}}{n_{j}+\lambda_{j} \sigma_{j}}}{\sum_{k} \widehat{\eta}_{j} A_{j}+(1+r)^{2} \sum_{j}\left(\widehat{\eta}_{j}-\eta_{j}\right) \frac{\lambda_{j} \theta_{j}}{n_{j}+\lambda_{j} \sigma_{j}}}\right\} \\
& =\left(\widehat{\eta}_{k}-\eta_{k}\right)\left\{\frac{\sum_{k} \widehat{\eta}_{j} A_{j}}{\sum_{k} \widehat{\eta}_{j} A_{j}+(1+r)^{2} \sum_{j}\left(\widehat{\eta}_{j}-\eta_{j}\right) \frac{\lambda_{j} \theta_{j}}{n_{j}+\lambda_{j} \sigma_{j}}}\right\}
\end{aligned}
$$

As

$$
A_{j}+(1+r)^{2} \frac{\lambda_{j} \theta_{j}}{n_{j}+\lambda_{j} \sigma_{j}}=r+\frac{\lambda_{k}\left(1-\theta_{k}\right) x_{k} r_{k}^{\prime}}{n_{k}+\lambda_{k} \sigma_{k}}<0,
$$

the expression into brackets in (52) is positive. As a consequence $\Gamma_{k}$ has the sign of $\left(\widehat{\eta}_{k}-\eta_{k}\right)$ so we finally obtain point ii of Proposition 2:

$$
\Gamma_{k} \geqslant 0 \Leftrightarrow \beta_{k} \geqslant \beta_{m}=\sum_{j} \eta_{j} \beta_{j}
$$




\section{References}

[1]Crettez, B. and MC. Fagart (2005), "A note on the Pareto efficiency of general oligopolistic equilibria", Working Paper Crest

[2]Farrel, J. and C. Shapiro (1990), "Horizontal mergers: an equilibrium analysis", American Economic Review, 80, 107-126.

[3]Dixit, A. and J. Stiglitz (1977), "Monopolistic competition and optimum product diversity", American Economic Review, 67, 3 (June), 297-308.

[4]Kass, L. (2001), "Cournot-Walras equilibrium without profit feedback", Economics bulletin, vol 4, 9, 1-8.

[5]Konishi, H. M. Okuno-Fujiwara and K. Suzumura (1990), "Oligopolistic competition and economic welfare", Journal of Public Economics, 42,67-88.

[6]François J. and H. Horn (2000): "Competition policy in an open economy", Working Paper

[7]Myles, G. (2001): "Consumer and trade prices in general equilibrium with imperfect competition" Working paper.

[8]Neary, P. (2002a), "Competition, trade and wages", in D. Greenaway, R. Upward and K. Wakelin (eds) : Trade, Migration and Labour Market Adjustement, London: Macmillan, 28-45.

[9]Neary, P. (2002b), "Foreign competition and wage inequality", Review of International Economics, 10, 680-93.

[10]Neary, P. (2003,a), "Competitive versus comparative advantage", The World Economy, 26, 4, April , 457-470.

[11]Neary, P. (2003,b), "The road less travelled: olipoly and competition policy in general equilibrium", in R. Arnott, B. Greenwald, R. Kanbur, B. Nabeluff. Cambridge (eds): Imperfect Economics: Essays in Honor of Joseph Stiglitz, Mass, MIT Press, 485-500.

[12]Neary, P. (2003,c), "International trade in general oligopolistic equilibrium", Working Paper. 
[13]Negishi, T. (1961), "Monopolistic Competition and General Equilibrium", Review of Economic Studies.

[14]Posner R. (2001), "Antitrust and the New Economy", Antitrust Law Journal, 68, 925.

[15]Rey P. (2003), "Towards a theory of competition policy", Advances in Economics and Econometrics: Theory and Applications, Eight World Congress, M. Dewatripont, L.P. Hansen, S.J. Turnovsky eds, Cambridge University Press 
Graphic 1 